\title{
US still vague about Geneva agreement
}

\section{Washington}

Fusion energy researchers in the United States were optimistic last week that the accord reached in Geneva between President Ronald Reagan and Soviet leader Mikhail Gorbachev on magnetic fusion would lead to increased contacts with their Soviet counterparts. Details of what exactly has been agreed were sparse last week, but the two leaders advocated "the widest possible international cooperation" on development of magnetic fusion power. There are still formidable obstacles, however, in the way of building a joint fusion research reactor.

Fusion research does not rank high

Honour for honoured THE Technical University in Munich (TUM) is trying to woo back Klaus von Klitzing, winner of this year's Nobel Prize for Physics (see Nature 24 October, p.667) by offering him the directorship of a new institute in semiconductor physics. Setting-up costs for the institute are estimated at more than DM20 million, of which it is hoped industry will provide onethird, the other two-thirds coming from the Bavarian state government. Von Klitzing is said to have indicated interest, but is undecided about accepting.

From 1980 to 1984, von Klitzing was an associate professor at TUM but in a reorganization of the physics faculty he was not promoted to a full professorship, so he accepted a directorship at the Max Planck Institute of solid-state physics in Stuttgart. At the new institute, he would be a full professor and will have the opportunity to teach, which he is said to want.

The institute will be set up to provide the most advanced research facilities. It will be divided into three sections, each headed by a director - von Klitzing's colleague Frederik Koch, who proposed the original idea for the institute, has been invited to lead one of those sections. The plan also includes six scientists and nine technicians as well as administrative and secretarial staff. All of these are new positions and have to be included in TUM's next budget. Land is already available but finance for a new building and equipment will be discussed early in December when the state government meets with various industrial concerns.

The institute will be named after the Berlin physicist Walter Schottky. TUM intends to do all it can to lure von Klitzing back, not just because of his recent honour, but because it considers semiconductor physics an important field. Jen Altman among the issues needing discussion between the superpowers, which perhaps explains the vagueness of the public statements, although further details may yet emerge. It will be for the Department of Energy to draw up detailed proposals for an agenda on collaboration, which could be discussed when Reagan and Gorbachev meet next year in the United States.

There are several reasons why magnetic fusion is a good candidate for international cooperation. Most of the literature is unclassified and the next generation of research machines (which will seek to attain plasma ignition, the point at which fusion becomes self-sustaining) will be enormously expensive.

The US magnetic fusion research budget, though faring well by comparison with other energy research projects, has declined substantially in recent years, from $\$ 464$ million in 1984 to $\$ 429$ million in 1985 , with the budget for fiscal year 1986 down to $\$ 382$ million. The programme's goals have correspondingly been pushed into the future. Dr Harold Furth, head of the Princeton Tokamak Fusion Test Reactor, says that because of budget constraints, plans to introduce tritium (the fusion fuel) into the Princeton reactor have been put back until at least the end of 1988. No decisions have been made on a new research machine for the United States in 10 years. Cooperation with the Soviets would be one way to make a limited budget go further.

Soviet magnetic fusion research is comparable with that in the United States. Collaboration takes place at present under an intergovernmental bilateral agreement first negotiated in 1973 and extended in 1983. The number and the standing of scientists in reciprocal exchanges are, however, widely believed to have declined in recent years (partly because of protests over Soviet human rights abuses and its invasion of Afghanistan). There were six scientific teams exchanged last year. Dr Frank Press, president of the National Academy of Sciences (NAS) (whose personal efforts to further individual US-Soviet exchanges have been criticized by anti-Soviet hardliners in the Pentagon) said the Reagan-Gorbachev agreement will affect exchanges "productively".

In the short term, there are likely to be many benefits from increased cooperation on basic plasma physics research and on design and engineering of fusion equipment and diagnostics. But if increasing the frequency of scientific visits is a feasible goal, there remain serious difficulties for cooperation on a fusion reactor. Dr John
Richardson of NAS says that a role can be seen for two machines, one to demonstrate plasma ignition and a second to examine engineering concepts for a future commercial reactor. And there are several ancillary projects that might be tackled as collaborative ventures, such as compact toruses, magnetic mirror fusion and hybrid reactors whose neutron flux would be used to manufacture fuel for con ventional fission reactors.

But Richardson can see no "natural division of labour" for a truly international four-way agreement to include Europe, the United States, the Soviet Union and Japan; so far, it has not even been possible to negotiate such a deal with Europe.

Tim Beardsley

\section{Geneva summit}

\section{Soviet optimism on fusion plan}

THE Soviet response to the prospect that the Geneva summit could lead to increased scientific cooperation has been slower than that in the United States, but is no less enthusiastic. Mr Mikhail Gorbachev himself has been reluctant to "deal with the nuances" of possible cooperation projects, as he phrased it at Geneva last week, preferring to stress the funds that could be released to fight world hunger if the arms race were halted. Indeed, when he did commit himself on a specific project - fusion research - what he had in mind was not bilateral but multilateral cooperation. "It was decided", he said, "jointly to approach a number of other states about cooperation in the field of thermonuclear research. This is a very interesting idea which could guarantee for mankind an inexhaustible source of energy."

The view of the Soviet scientific community was reflected last week in Moscow by Dr Petr Timofeev, deputy director of the Institute of Geology of the Academy of Sciences, who said that the institute had been involved in a number of cooperation projects with the United States on the geology of the oceans which had, regretfully, been curtailed in recent years, but would now, he hoped, be renewed. Other potential fields of cooperation in which Soviet scientists are interested include space research, the "conquest of human disease", the environment (a delegation from the US Environmental Protection Agency visited the Soviet Union just before the Geneva summit) and. of course, controlled thermonuclear fusion.

If this cooperation project does materialize, it could prove a particular blessing to Academician Evgenii Velikhov, head of the Soviet nuclear fusion programme. Velikhov is a great advocate of international cooperation on fusion. It was he who put the proposal for the INTOR international tokamak project to the International Atomic Agency.

Vera Rich 